\begin{abstract}
Aims: Annexin 1 (ANXA1), a member of the annexin family of calcium-binding and phospholipid-binding proteins, is a key mediator of the anti-inflammatory actions of steroid hormones. We have previously demonstrated that, in the human lymphoblastic CCRF-CEM cell line, both the synthetic glucocorticoid hormone, dexamethasone (Dex), and the estrogen hormone, 17 $\beta$-estradiol $\left(E_{2} \beta\right)$, induce the synthesis of ANXA1, by a mechanism independent of the activation of their nuclear receptors. Recently, it was reported that the gene coding for ANXA1 contains a cAMP-responsive element (CRE). In this work, we investigated whether Dex and $E_{2} \beta$ were able to induce the activation of CRE binding proteins (CREB) in the CCRF-CEM cells. Moreover, we studied the intracellular signalling pathways involved in CREB activation and ANXA1 synthesis in response to Dex and $E_{2} \beta$ namely, the role of CAMP and the p38 mitogenactivated protein kinase (MAPK).

Results: The results show that Dex and $\mathrm{E}_{2} \beta$ were as effective as the cAMP analogue, DBCAMP, in inducing CREB activation. On the contravy, dBcAMP induced ANXA1 synthesis as effectively as these steroid hormones. Furthermore, the cAMP antagonist, Rp-8Br-cAMPS, and the specific p38 MAPK inhibitor, SB203580, effectively prevented both Dex-induced, $E_{2} \beta$-induced and dBcAMP-induced CREB activation and ANXA1 synthesis.

Conclusions: Taken together, our results suggest that, in CCRF-CEM cells, Dex-induced and $E_{2} \beta$-induced ANXA1 expression requires the activation of the transcription factor CREB, which in turn seems to be mediated by cAMP and the p38 MAPK. These findings also suggest that, besides the nuclear steroid hormone receptors, other transcription factors, namely CREB, may play important roles in mediating the anti-inflammatory actions of glucocorticoids and oestrogen hormones.
\end{abstract}

Key words: Annexin 1, CREB, $17 \beta$-Estradiol, Dexamethasone, cAMP, p38 MAPK

\section{Dexamethasone-induced and estradiol-induced CREB activation and annexin 1 expression in CCRF- CEM lymphoblastic cells: evidence for the involvement of cAMP and P38 MAPK}

\author{
M. Castro-Caldas ${ }^{1, C A}$, A. F. Mendes ${ }^{1,2}$, C. B. Duarte ${ }^{1}$ \\ and M. C. F. Lopes ${ }^{1,2}$
}

${ }^{1}$ Centre for Neuroscience and Cell Biology, University of Coimbra, 3004-517 Coimbra, Portugal and ${ }^{2}$ Faculty of Pharmacy, University of Coimbra, Portugal

\author{
${ }^{\mathrm{CA}}$ Corresponding author \\ Tel.: + 351239480236 \\ Fax: +351239480217 \\ E-mail: mcflopes@imagem.ibili.uc.pt
}

\section{Introduction}

Annexin 1 (ANXA1) (also known as lipocortin 1) is a member of the annexin family of calcium-binding and phospholipid-binding proteins, ${ }^{1,2}$ which is constitutively expressed in many human cells, particularly in polymorphonuclear leukocytes. ${ }^{1,3}$ Recently, we observed that ANXA1 is also constitutively expressed in a human lymphoblastic $\mathrm{T}$ cell line, the CCRF-CEM cell line. ${ }^{4}$ Although its biological role is still incompletely characterised, ANXA1 is considered an endogenous anti-inflammatory effector that mediates at least some of the anti-inflammatory actions of the glucorticoid (GC) hormones; namely, the inhibition of phospholipase $\mathrm{A}_{2}$, with the consequent suppression of prostaglandin and leukotriene production, ${ }^{1}$ the inhibition of superoxide generation, ${ }^{5}$ the inhibition of the activation, transmigration and phagocytic ability of neutrophils. ${ }^{3}$ Recently, ANXA1 has also been shown to mediate the inhibitory effect of GCs on the expression of cyclooxygenase-2 (COX$2),{ }^{6-8}$ an enzyme required for prostaglandin production and also involved in cell proliferation., ${ }^{9,10}$ Furthermore, some of the anti-inflammatory effects attributed to $17 \beta$-estradiol $\left(\mathrm{E}_{2} \beta\right)$, the most potent oestrogen hormone, are identical to those exerted by ANXA1, suggesting that this protein may also mediate the anti-inflammatory actions of $\mathrm{E}_{2} \beta{ }^{11,12}$

In resting cells ANXA1 is an intracellular protein, being secreted and resynthesised upon stimulation. Once in the extracellular medium, ANXA1 binds, in a paracrine or autocrine way, to specific plasma membrane binding sites, which are considered to mediate its biological actions. ${ }^{5,13}$ Consistent with the 
notion that ANXA1 mediates some of the antiinflammatory actions of GCs, these hormones, most remarkably the synthetic GC dexamethasone (Dex), have been shown to potently induce ANXA1 secretion and synthesis in many different cells. ${ }^{14,15}$ Our own observations also show that both $\operatorname{Dex}^{16}$ and $\mathrm{E}_{2} \beta^{4}$ induce the rapid secretion of ANXA1, followed by its de novo synthesis, in the human lymphoblastic CCRFCEM cells.

The intracellular signalling pathways utilised by either the GC or the oestrogen hormones to induce ANXA1 synthesis are still poorly understood. Many actions of these hormones are mediated through genomic mechanisms involving their respective nuclear receptors, which, upon binding the hormone, act as transcription factors directly modulating the transcription of genes containing in their promoter regions either a GC responsive element (GRE) or an oestrogen responsive element. ${ }^{17,18}$ Using the potent GC receptor antagonist RU486 (mifepristone), some studies showed that, in some cells, the synthesis of ANXA1 is dependent on GC receptors, ${ }^{2,19}$ whereas the opposite was found in other cells. ${ }^{20,21}$ Therefore, some authors have suggested that the putative GRE that is present in the promoter region (intron I) of the ANXA1 gene is non-functional. ${ }^{22,23}$ In our previous work, we also found no evidence supporting the involvement of such nuclear hormone receptors in either Dex-induced or $\mathrm{E}_{2} \beta$-induced ANXA1 synthesis in CCRF-CEM cells. ${ }^{4,16}$

Besides the putative GRE, it was recently shown that the promoter region of the ANXA1 gene contains a cAMP-responsive element (CRE) and that a CREbinding protein (CREB) is required for either Dexinduced or cAMP-induced ANXA1 synthesis. $^{22}$ Furthermore, Dex and $E_{2} \beta$ have also been shown to induce the transcription of several genes by activating CREB. ${ }^{22,24,25}$

The phosphorylation and consequent activation of CREB can be regulated by several intracellular signalling pathways. Among those, CAMP ${ }^{26,27}$ and the p38 mitogen-activated protein kinase (MAPK) ${ }^{28,29}$ seem to play crucial roles in the activation of CREB in different cells. Interestingly, various studies showed that Dex and $\mathrm{E}_{2} \beta$ can stimulate adenylate cyclase activity, thus increasing the production of CAMP, ${ }^{30-33}$ which is also an inducer of ANXA1 synthesis in some cell types. ${ }^{22,34,35}$ Moreover, recent reports indicate that, in different cells, Dex and $E_{2} \beta$ can up-regulate the activity of the p38 MAPK. ${ }^{36-38}$

In an attempt to understand the mechanisms by which Dex and $E_{2} \beta$ induce the synthesis of ANXA1, we have investigated the ability of these two steroid hormones to activate CREB in the CCRF-CEM cells. Moreover, to further elucidate the signalling pathways involved, we also studied the role of cAMP and of the p38 MAPK on Dex-induced and $\mathrm{E}_{2} \beta$-induced CREB activation and ANXA1 expression.

\section{Materials and methods}

\section{Chemicals}

The human CCRF-CEM acute $\mathrm{T}$ lymphoblastic leukaemia cell line was purchased from American Type Culture Collection (Rockville, MD, USA). Foetal calf serum (FCS) was obtained from Biochrom (Berlin, Germany). Dibutyryl-cAMP (dBcAMP) was from BIOMOL (USA). Adenosine 3',5'-cyclic monophosphorothioate, 8-bromo, Rp-isomer, sodium salt (Rp-8-Br-cAMPS) and SB203580 were purchased from Calbiochem (San Diego, CA, USA). The protease inhibitor cocktail was obtained from Roche (Manheim, Germany). The oligonucleotide probes were from Santa Cruz (Santa Cruz, CA, USA). $\left[\gamma^{-32} \mathrm{P}\right]$ adenosine triphosphate, T4 polynucleotide kinase and poly $(\mathrm{dI}-\mathrm{dC}) \cdot(\mathrm{dI}-\mathrm{dC})$ were obtained from Pharmacia Biosciences (Piscataway, NJ, USA). The mouse monoclonal antibody against ANXA1 (Clone Lipo 105) was purchased from BabCO (CA, USA). The FITC-conjugated rabbit anti-mouse antibody and the normal rabbit serum were obtained from DAKO (Copenhagen, Denmark). All other reagents were from Sigma Chemical Co. (St Louis, MO, USA).

\section{Culture conditions}

The human CCRF-CEM acute $\mathrm{T}$ lymphoblastic leukaemia cell line was maintained in RPMI medium supplemented with $10 \%(\mathrm{v} / \mathrm{v})$ FCS, $100 \mu \mathrm{g} / \mathrm{ml}$ streptomycin and $100 \mathrm{U} / \mathrm{ml}$ penicilin, at $37^{\circ} \mathrm{C}$, in an atmosphere of $5 \% \mathrm{CO}_{2} / 95 \%$ air. Prior to any treatments, CCRF-CEM cells were plated at $5 \times 106$ cells/ well, in six-well culture plates, in RPMI supplemented with antibiotics and $0.5 \%$ FCS, for at least $5 \mathrm{~h}$, and maintained in these conditions thereafter. In each experiment, controls consisting of cells incubated in the corresponding volume of culture medium plus the appropriate vehicle were always included.

\section{Cell viability}

The viability of CCRF-CEM cells, under the various experimental conditions, was always assessed by the trypan blue exclusion method and the 3-(4,5-dimethylthiazol-2-yl)-2,5-diphenyl tetrazolium bromide (MTT) reduction assay. Assessment of MTT reduction by metabolically active cells was made by a colorimetric assay, as previously described. ${ }^{39}$

\section{Preparation of cytoplasmic and nuclear extracts}

After washing with ice-cold phosphate-buffered saline (PBS), the cells were lysed in 'buffer 1' $(10 \mathrm{mM}$ $\mathrm{NaCl}, 3 \mathrm{mM} \mathrm{MgCl}_{2}, 0.5 \%(\mathrm{v} / \mathrm{v})$ Nonidet P- $40,1 \mathrm{mM}$ dithiothreitol, $0.1 \mathrm{mM}$ phenylmethylsulfonylfluoride, $10 \mathrm{mM}$ Tris $-\mathrm{HCl}, \mathrm{pH} 7.5$, and the protease inhibitor 
cocktail) and incubated on ice, for $15 \mathrm{~min}$. After brief vortexing, the lysates were centrifuged at $2300 \times \mathrm{g}$, for $10 \mathrm{~min}$, at $4^{\circ} \mathrm{C}$. The supernatants, cytoplasmic extracts, were collected and stored at $-70^{\circ} \mathrm{C}$ until further use. The pellets obtained were resuspended in 'buffer 2' (300 mM NaCl, $3 \mathrm{mM} \mathrm{MgCl}_{2}, 20 \%$ (v/v) glycerol, $1 \mathrm{mM}$ dithiothreitol, $0.1 \mathrm{mM}$ phenylmethylsulfonylfluoride, $0.2 \mathrm{mM}$ ethylenediamine tetraacetic acid (EDTA), $20 \mathrm{mM}$ HEPES buffer, $\mathrm{pH} 7.5$, and the protease inhibitor cocktail), incubated on ice for 45 min and centrifuged at $12,000 \times \mathrm{g}$, for $20 \mathrm{~min}$, at $4^{\circ} \mathrm{C}$. The supernatants, nuclear extracts, were also collected and stored at $-70^{\circ} \mathrm{C}$ until further use. The protein concentration of the extracts was determined using the bicinchoninic acid/copper (II) sulphate protein assay kit.

\section{Electrophoretic mobility shift assay}

The oligonucleotide probes containing either the consensus binding sequence corresponding to the CRE (5'-AGA GAT TGC CTG ACG TCA GAG AGC TAG-3') or a mutated inactive form of this oligonucleotide (5'-AGA GAT TGC CTG TGG TCA GAG AGC TAG-3') were end-labelled with $\left[\gamma_{-}{ }^{32} \mathrm{P}\right]$ adenosine triphosphate, by the $\mathrm{T} 4$ polynucleotide kinase, and purified through Sephadex G-50 spin columns. Nuclear extracts $(12.5 \mu \mathrm{g}$ protein) were incubated, for $40 \mathrm{~min}$, at $4^{\circ} \mathrm{C}$, with $100,000 \mathrm{cpm}$ of the $\left[\gamma^{-}{ }^{32} \mathrm{P}\right]-$ labelled oligonucleotide, in a buffer containing 100 $\mu / \mathrm{ml}$ poly $(\mathrm{dI}-\mathrm{dC}) \cdot \operatorname{poly}(\mathrm{dI}-\mathrm{dC}), 20 \mathrm{mM}$ HEPES $(\mathrm{pH}$ 7.9), $1 \mathrm{mM} \mathrm{MgCl}_{2}$, 4\% (v/v) Ficoll 400, $0.5 \mathrm{mM}$ dithiothreitol, $50 \mathrm{mM} \mathrm{KCl}$, and $1 \mathrm{mg} / \mathrm{ml}$ barine serum albumin. The DNA-protein complexes were resolved by electrophoresis on $7 \%$ non-denaturating polyacry-lamide gels, in a buffer system containing $0.044 \mathrm{M}$ Tris-Base (pH 8.0), $4.45 \mathrm{mM}$ boric acid and 1 mM EDTA, at constant voltage of $150 \mathrm{~V}$, for $3 \mathrm{~h}$, at room temperature. The gels were then dried and subjected to autoradiography. In competition experiments, a 100-fold excess of unlabelled oligonucleotide was added to the nuclear extracts immediately before the addition of the radiolabelled probe.

\section{Immunocytochemistry assay}

After washing in ice-cold PBS, the cells were spread on poly-D-lysine-coated glass slides and air-dried for $30 \mathrm{~min}$. The cells were then fixed $(4 \%(\mathrm{w} / \mathrm{v})$ paraformaldehyde and 2\%(w/v) sucrose in PBS), for $15 \mathrm{~min}$, and permeabilised (1\% Triton-XlOO in PBS), for 5 min. Background blocking was performed with normal rabbit serum, and detection of total ANXA1 was performed by incubation with a mouse monoclonal anti-ANXA1 antibody $(4 \mu \mathrm{g} / \mathrm{ml})$. After extensive rinsing in PBS, the cells were incubated with a FTTC-conjugated rabbit anti-mouse antibody. We have previously confirmed the specificity of this
anti-ANXA1 antibody by western blot analysis. ${ }^{4,16}$ Serum and antibodies were diluted in PBS with $0.5 \%$ $(\mathrm{w} / \mathrm{v})$ bovine serum albumin and $0.2 \%(\mathrm{v} / \mathrm{v})$ Tween20 , and all the incubations were performed at room temperature, in a humidified chamber. Control experiments for non-specific binding were performed in parallel by omission of the primary antibody.

\section{Results}

\section{Dex, $E_{2} \beta$ and $d B c A M P$ induce CREB activation}

To evaluate CREB activation we used electrophoretic mobility shift assay (EMSA) analysis to detect the presence of active CREB proteins, capable of forming complexes with a $\left[\gamma_{-}{ }^{32} \mathrm{P}\right]$-labelled oligonucleotide probe containing the specific consensus binding sequence for this transcription factor. The oligonucleotide used corresponds to the CRE present in the promoter region of target genes.

CCRF-CEM cells were cultured in RPMI medium supplemented with $0.5 \%$ FCS, and treated with Dex $(1 \mu \mathrm{M}), \mathrm{E}_{2} \beta(1 \mu \mathrm{M})$ or with the stable cell-permeable cAMP analogue dBcAMP ( $1 \mathrm{mM}$ ) for $15 \mathrm{~min}, 30 \mathrm{~min}$ or $1 \mathrm{~h}$. The respective nuclear extracts were used for EMSA analysis. The results obtained show the presence of retarded bands, the intensity of which was much higher in the nuclear extracts from cells treated with Dex (Fig. 1), $\mathrm{E}_{2} \beta$ (Fig. 2) or dBcAMP (Fig. 3) than in those from control untreated cells (Figs. 1-3, lane 1). For each stimulus, the intensity of those bands varied with the incubation time and was maximal when the cells were treated with Dex for 1 h (Fig. 1, lane 4), $\mathrm{E}_{2} \beta$ for $30 \mathrm{~min}$ (Fig. 2, lane 3), or dBcAMP for 15 min (Fig. 3, lane 2). Therefore, for each one of these three stimuli, the respective optimal incubation time was used in all subsequent experiments.

The specificity of the complexes formed was evaluated by incubating the nuclear extracts from Dex-treated, $\mathrm{E}_{2} \beta$-treated or dBcAMP-treated cells with a $\left[{ }^{32} \mathrm{P}\right]$-labelled mutant $\mathrm{CREB}$ oligonucleotide probe that differs in two bases from the native CREB oligonucleotide. As shown in lane 5 of Figs. 1-3, no specific CREB complexes could be detected under these experimental conditions. Furthermore, competition assays performed by incubation of the nuclear extracts with the $\left[{ }^{32} \mathrm{P}\right]$-labelled CREB oligonucleotide probe and with a 100-fold excess of unlabelled oligonucleotide probes, specific for either CREB, mutant CREB or an unrelated transcription factor, octamer (Oct-1), showed that only the unlabelled CREB probe was effective in preventing the formation of specific complexes between the proteins present in the nuclear extracts and the labelled CREB probe (Figs 1-3, lanes 6-8). These results indicate that the retarded bands detected in lanes 1-4 


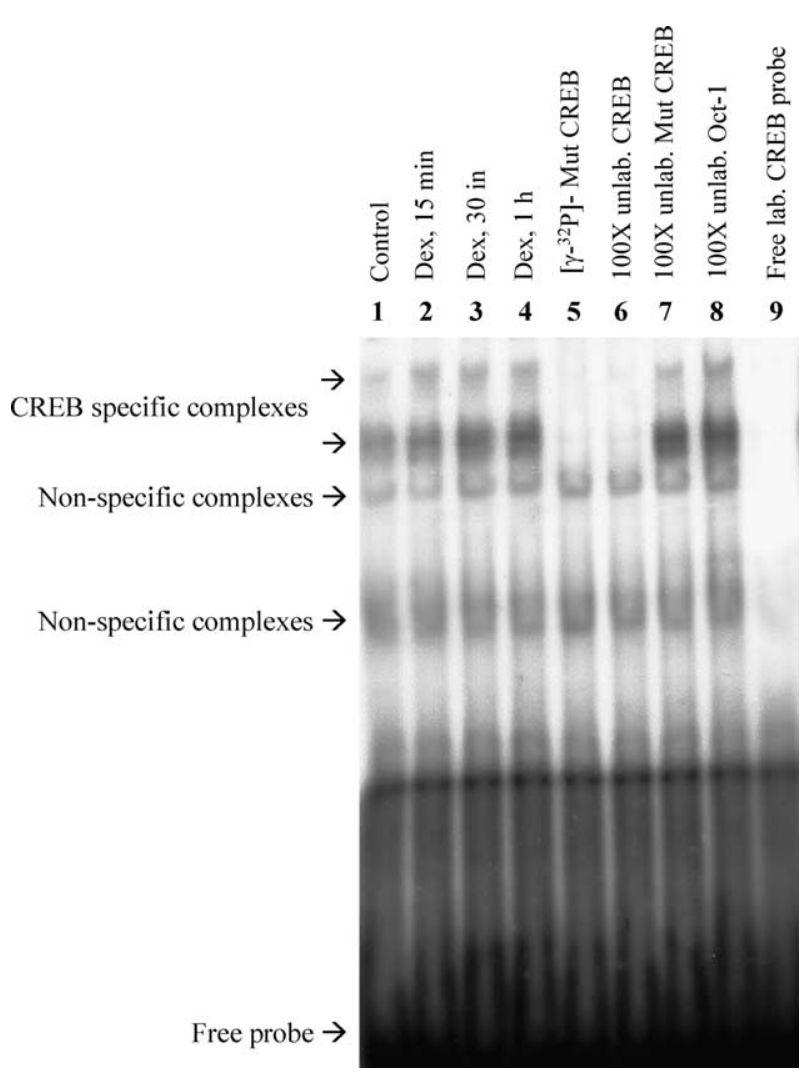

FIG. 1. Dex induces CREB activation in CCRF-CEM cells. The cells were treated with Dex $(1 \mu \mathrm{M})$ (lanes $2-4)$, for $15 \mathrm{~min}, 30$ min or $1 \mathrm{~h}$, or left untreated (control, lane 1). Nuclear extracts were subjected to EMSA analysis as described in Materials and methods. Competition experiments with a 100 -fold excess of unlabelled competitor probe relative to the labelled CREB probe were performed using the nuclear extracts from cells treated with Dex, for I h (lanes 6-8). EMSA analysis was also performed using a labelled mutant CREB probe (lane 5). The results shown are representative of three independent experiments.

of the autoradiographies presented in Figs. 1-3 represent the formation of specific complexes between CREB proteins and the CREB-specific oligonucleotide probe.

\section{CREB activation, induced by Dex, $E_{2} \beta$ or dBcAMP, is inhibited by the cAMP antagonist, Rp-8-Br-cAMPS}

In order to investigate whether cAMP is required for the activation of CREB induced by Dex, $E_{2} \beta$ or dBcAMP, we used the potent cAMP antagonist Rp-8Br-cAMPS, which is metabolically stable and cell permeable. ${ }^{40}$ CCRF-CEM cells were pre-treated with Rp-8-Br-cAMPS $(500 \mu \mathrm{M})$, for $1 \mathrm{~h}$, before the addition of Dex, $E_{2} \beta$ or dBcAMP, and then further incubated for $1 \mathrm{~h}, 30 \mathrm{~min}$ or $15 \mathrm{~min}$, respectively. Assessment of the cell viability by the MTT reduction assay showed that Rp-8-Br-cAMPS did not reduce the viability of the CCRF-CEM cells relatively to untreated cells (data not shown), thus indicating the absence of toxic effects in the experimental conditions used. The results pre-


FIG. 2. $E_{2} \beta$ induces CREB activation in CCRF-CEM cells. The cells were treated with $E_{2} \beta(1 \mu \mathrm{M})$ (lanes $\left.2-4\right)$, for $15 \mathrm{~min}, 30$ min or $1 \mathrm{~h}$, or left untreated (control, lane 1). Nuclear extracts were subjected to EMSA analysis as described in Materials and methods. Competition experiments with a 100-fold excess of unlabelled competitor probe relatively to the labelled CREB probe were $C$ performed using the nuclear extracts from cells treated with $E_{2} \beta$, for 30 min (lanes 6-8). EMSA analysis was also performed using a labelled mutant CREB probe (lane 5). The results shown are representative of three independent experiments.

sented in Fig. 4 show that pre-treatment of the cells with Rp-8-Br-cAMPS effectively prevented Dex-induced, $\mathrm{E}_{2} \beta$-induced and dBcAMP-induced CREB activation, as indicated by the reduced intensity of the bands corresponding to the specific CREB complexes (lanes 3, 5 and 7). Treatment of the cells with Rp-8-Br-cAMPS alone had no effect on the basal activation of CREB observed in nuclear extracts from control cells (data not shown).

ANXA1 expression, induced by either Dex, $E_{2} \beta$ or $\mathrm{dBcAMP}$, is inhibited by the cAMP antagonist Rp-8-Br-cAMPS

ANXA1 expression was evaluated by immunocytochemistry in permeabilised CCRF-CEM cells. This method allowed us to detect total ANXA1, which corresponds to the intracellular protein plus the protein bound to its specific binding sites located on the outer surface of CCRF-CEM cells plasma membrane. 


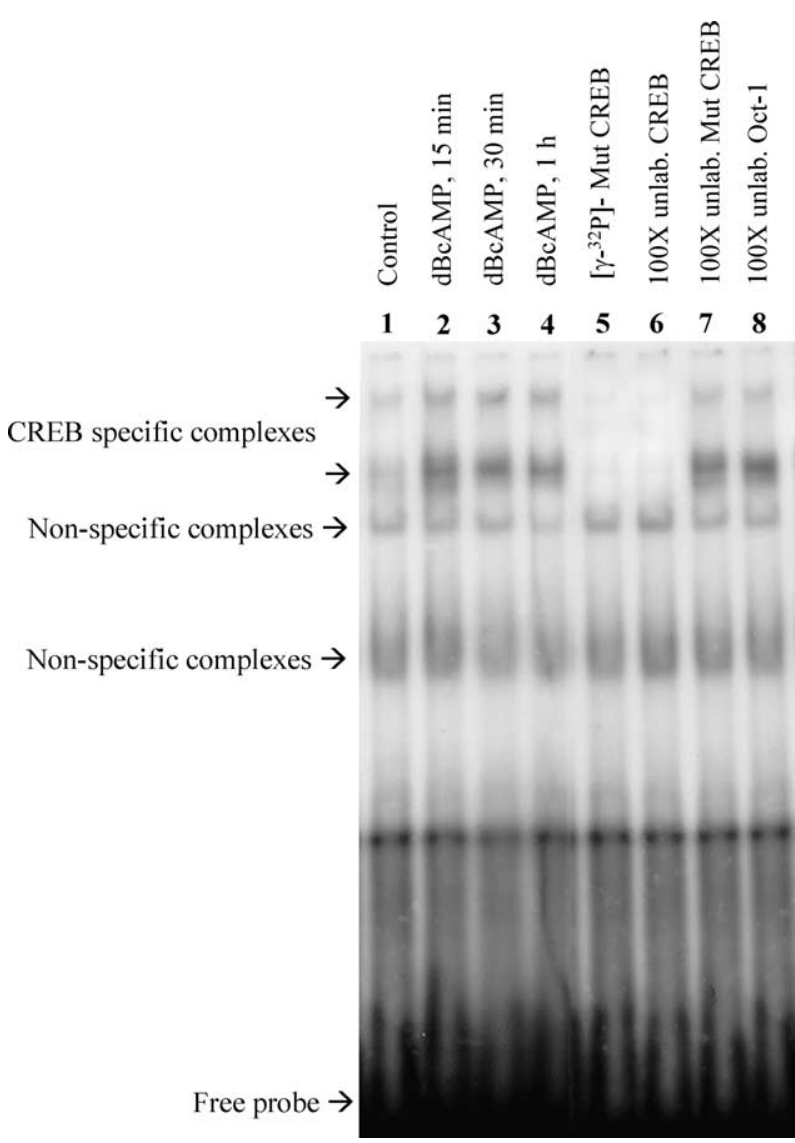

FIG. 3. dBcAMP induces CREB activation in CCRF-CEM cells. The cells were treated with dBcAMP $(1 \mathrm{mM})$ (lanes $2-4)$, for $15 \mathrm{~min}, 30 \mathrm{~min}$ or $1 \mathrm{~h}$, or left untreated (control, lane 1). Nuclear extracts were subjected to EMSA analysis as described in Materials and methods. Competition experiments with a 100 -fold excess of unlabelled competitor probe relatively to the labelled CREB probe were performed using the nuclear extracts from cells treated with dBcAMP, for 15 min (lanes 6-8). EMSA analysis was also performed using a labelled mutant CREB probe (lane 5). The results shown are representative of three independent experiments.

We have previously shown that Dex significantly increases the cellular content of ANXA1, upon stimulation of CCRF-CEM cells for $12 \mathrm{~h} .^{16}$ Therefore, in this work the cells were treated with Dex $(1 \mu \mathrm{M})$, $\mathrm{E}_{2} \beta(1 \mu \mathrm{M})$ or dBcAMP $(1 \mathrm{mM})$, for $12 \mathrm{~h}$, for the detection of total ANXA1 by immunocytochemistry.

The results obtained showed that control untreated CCRF-CEM cells have a weak basal fluorescent staining for ANXA1 (Fig. 5A), which corresponds to the constitutive expression of this protein. In cells treated with Dex or $\mathrm{E}_{2} \beta$, for $12 \mathrm{~h}$, there was a marked increase of the fluorescent staining for total ANXA1 (Fig. 5B,C). A similar increase of the total ANXA1 immunoreactivity was also observed in cells treated with dBcAMP for the same time period (Fig. 5D). Taken together, these results show that Dex, $\mathrm{E}_{2} \beta$ and dBcAMP increase the total cellular content of ANXA1, indicating that these compounds induce the expression of ANXA1 in CCRF-CEM cells.

To investigate whether cAMP mediates Dex-induced and $\mathrm{E}_{2} \beta$-induced ANXA1 expression, the cells

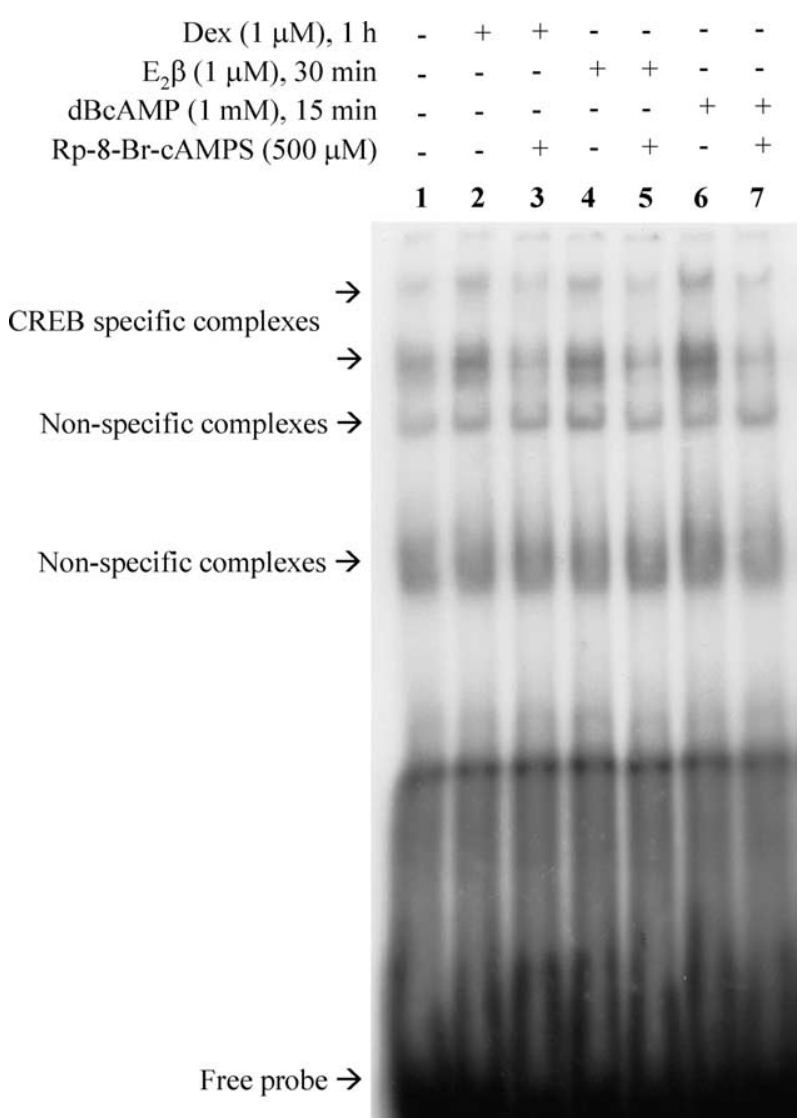

FIG. 4. Rp-8-Br-cAMPS inhibits Dex-induced, $E_{2} \beta$-induced and dBCAMP-induced CREB activation in CCRF-CEM cells. The cells were incubated in the presence or in the absence (control, lane 1) of the cAMP antagonist Rp-8-Br-cAMPS (500 $\mu \mathrm{M})$, for $1 \mathrm{~h}$. Then, the cells were further incubated with Dex $(1 \mu \mathrm{M}), \mathrm{E}_{2} \beta(1 \mu \mathrm{M})$ or dBcAMP $(1 \mathrm{mM})$ for $\mathrm{I} h, 30 \mathrm{~min}$ or 15 min, respectively. Nuclear extracts were subjected to EMSA analysis as described in Materials and methods. The results shown are representative of three independent experiments.

were pre-treated with Rp-8-Br-cAMPS $(500 \mu \mathrm{M})$, for 1 $\mathrm{h}$, before the addition of those stimuli, for another 12 h. The results presented in Fig. $5 \mathrm{E}-\mathrm{G}$ show that in cells pre-treated with Rp-8-Br-cAMPS the fluorescent staining for ANXA1 was similar to that of control cells, indicating that this cAMP antagonist is effective in preventing the synthesis of ANXA1 induced by either Dex, $\mathrm{E}_{2} \beta$ or dBcAMP. Rp-8-Br-cAMPS alone had no effect on the basal immunoreactivity for ANXA1 (data not shown).

\section{The p38 MAPK inhibitor SB203580 prevents} Dex-induced, $E_{2} \beta$-induced and dBcAMP-induced CREB activation and ANXA1 expression

To further elucidate the mechanism by which Dex, $\mathrm{E}_{2} \beta$ and $\mathrm{dBCAMP}$ induce CREB activation and ANXA1 expression, we studied the involvement of the p38 MAPK on this pathway. For this purpose we used SB203580, which is a pyridinyl imidazole compound shown to specifically inhibit the activity of the p38 MAPK. ${ }^{41-43}$ SB203580 $(40 \mu \mathrm{M})$ did not reduce the 

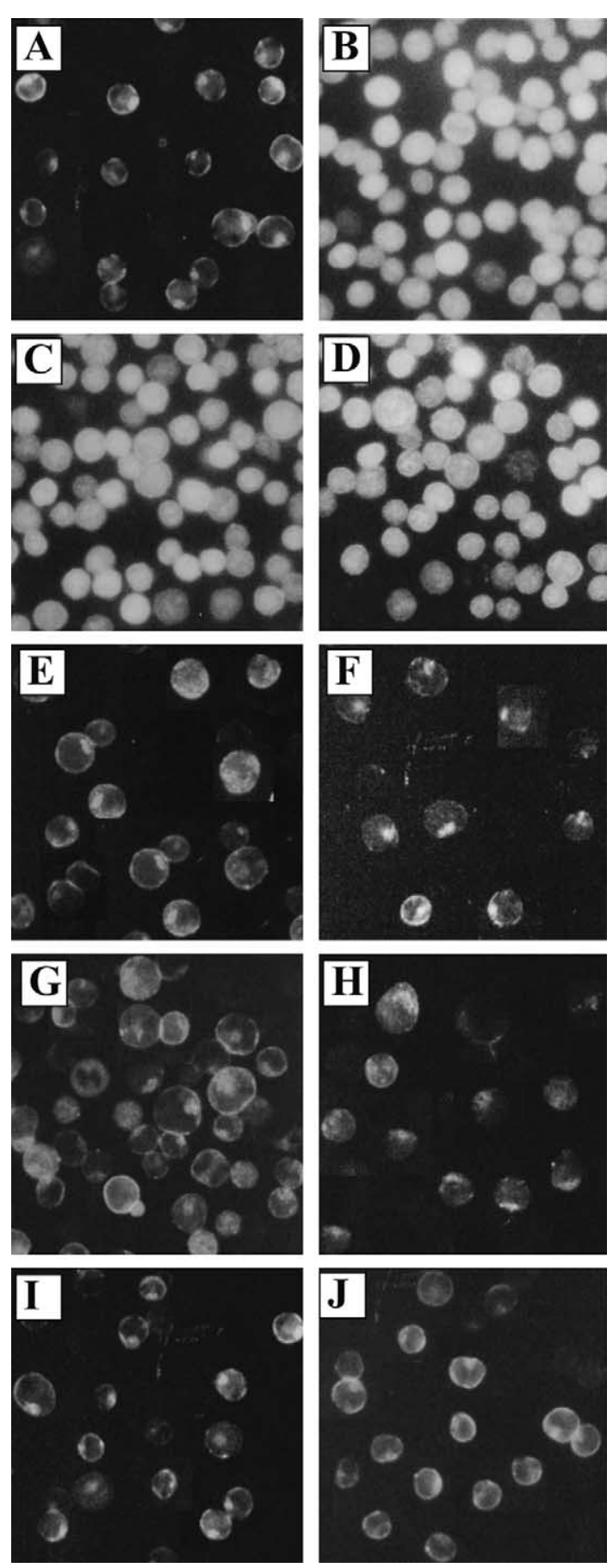

FIG. 5. Rp-8-Br-cAMPS and SB203580 inhibit the expression of ANXA1 induced by Dex, $E_{2} \beta$ or dBcAMP in CCRF-CEM cells. The cells were pre-treated with Rp-8-Br-cAMPS (500 $\mu \mathrm{M})$ or with SB203580 $(40 \mu \mathrm{M})$, for $1 \mathrm{~h}$, before the addition of Dex $(1 \mu \mathrm{M}), E_{2} \beta(1 \mu \mathrm{M})$ or dBcAMP $(1 \mathrm{mM})$, for $12 \mathrm{~h}$. The detection of total ANXA1 was performed by immunocytochemistry, as described in Materials and methods. (A) control, untreated cells; (B) cells treated with Dex; (C) cells treated with $E_{2} \beta$; (D) cells treated with dBcAMP; (E) cells treated with Rp-8-Br-cAMPS plus Dex; $(F)$ cells treated with $\mathrm{Rp}$-8-Br-cAMPS plus $\mathrm{E}_{2} \beta$; (G) cells treated with $\mathrm{Rp}-8-\mathrm{Br}$ cAMPS plus dBcAMP; $(\mathrm{H})$ cells treated with SB203580 plus Dex; (I) cells treated with SB203580 plus $\mathrm{E}_{2} \beta$; (J) cells treated with SB203580 plus dBcAMP. The results shown are representative of three independent experiments.

viability of the CCRF-CEM cells, as assessed by the MTT reduction assay (data not shown), indicating the absence of toxic effects in the experimental conditions used.

To study the involvement of the p38 MAPK on CREB activation, CCRF-CEM cells were pre-treated with SB203580 $(40 \mu \mathrm{M})$, for $1 \mathrm{~h}$, before the addition of Dex $(1 \mu \mathrm{M}), \mathrm{E}_{2} \beta(1 \mu \mathrm{M})$ or dBcAMP $(1 \mathrm{mM})$, and then further incubated for the optimal time periods previously identified for each stimulus (Figs. 1-3). The corresponding nuclear extracts were then subjected to EMSA analysis. The results presented in Fig. 6 show that pre-treatment of the cells with SB203580 was effective in preventing CREB activation induced by either Dex, $E_{2} \beta$ or dBcAMP, as indicated by the reduced intensity of the bands corresponding to the CREB specific complexes (lanes 3, 5 and 7). The involvement of the p38 MAPK on ANXA1 expression, induced by Dex, $\mathrm{E}_{2} \beta$ or ABcAMP, in CCRF-CEM cells was also evaluated by immunocytochernistry. The results showed that pre-treatment of the cells with SB203580 $(40 \mu \mathrm{M})$, for $1 \mathrm{~h}$, prior to the addition of Dex $(1 \mu \mathrm{M}), \mathrm{E}_{2} \beta(1 \mu \mathrm{M})$ or dBcAMP $(1 \mathrm{mM})$, for another $12 \mathrm{~h}$, effectively inhibited the increase in the fluorescent staining for total ANXA1 (Fig. 5H-J), as



FIG. 6. SB203580 inhibits Dex-induced, $E_{2} \beta$-induced and dBCAMP-induced CREB activation in CCRF-CEM cells. The cells were incubated in the presence or in the absence (control, lane 1) of the p38 inhibitor, SB203580 $(40 \mu \mathrm{A})$, for 1 $h$. Then, the cells were further incubated with $\operatorname{Dex}(1 \mu \mathrm{M}), \mathrm{E}_{2} \beta$ $(1 \mu \mathrm{M})$ or dBcAMP $(1 \mathrm{mM})$, for $1 \mathrm{~h}, 30 \mathrm{~min}$ or $15 \mathrm{~min}$, respectively. Nuclear extracts were subjected to EMSA analysis as described in Materials and methods. The results shown are representative of three independent experiments. 
compared with cells treated with Dex, $\mathrm{E}_{2} \beta$ or dBcAMP in the absence of the inhibitor (Fig. 5 B-D).

SB203580 alone had no effect on either the basal activation of CREB, or the basal expression of ANXA1 (data not shown).

\section{Discussion}

In this work, we found that both Dex and $\mathrm{E}_{2} \beta$ induce CREB activation, and that the CAMP analogue dBcAMP is as effective as Dex and $\mathrm{E}_{2} \beta$ in activating this transcription factor and in inducing ANXA1 synthesis, in CCRF-CEM cells. We also found that both the cAMP antagonist Rp-8-Br-cAMPS, and the p38 MAPK inhibitor SB 203580 effectively prevent CREB activation and ANXA1 synthesis induced by either Dex, $E_{2} \beta$ or the cAMP analogue dBcAMP. These results indicate that CAMP and the p38 MAPK are both required for Dex-induced and $\mathrm{E}_{2} \beta$-induced CREB activation and ANXA1 synthesis, and are also strong evidence that CREB activation is required for ANXA1 synthesis in these cells.

The intracellular signalling pathways involved in the expression of ANXA1 in response to steroid hormones are still incompletely understood. Although some reports show that GC hormones upregulate ANXA1 synthesis by genomic mechanisms, ${ }^{2,19}$ studies in different cells indicate that this effect is independent of the activation of nuclear GC receptors. ${ }^{20,21,23}$ In agreement with these latter results, our previous studies also indicate that, in CCRFCEM cells, ANXA1 synthesis is independent of either the nuclear GC receptors or the oestrogen receptors. ${ }^{4,16}$ Recently, it was shown that the gene coding for ANXA1, besides a putative GRE, also possesses a specific consensus binding sequence for CREB that was found to be essential for ANXA1 expression in a human choriocarcinoma-derived cell line. ${ }^{22}$

Many stimuli, acting in a variety of cells, increase the intracellular cAMP concentration, which leads to the activation of CREB by phosphorylation of the serine-133 residue. ${ }^{26,27}$ The results presented here show that Dex and $\mathrm{E}_{2} \beta$ were as effective as the cAMP analogue $\mathrm{dBcAMP}$ in activating CREB (Figs. 1-3). Although Dex and $E_{2} \beta$ mimicked the effects of dBcAMP, both hormones required longer incubation periods for maximal response, suggesting that cAMP has to be produced, in response to both steroids, before CREB activation can occur. In fact, these findings are in agreement with studies in other cell types showing that Dex and $\mathrm{E}_{2} \beta$ induce the production of cAMP, with variable kinetics, depending on the cell type. ${ }^{30-33}$ To further elucidate the role of cAMP on Dex-induced and $\mathrm{E}_{2} \beta$-induced CREB activation, we used the metabolically stable cell-permeant cAMP antagonist Rp-8-Br-cAMPS. ${ }^{40}$ Our results show that when CCRF-CEM cells were pre-treated with the CAMP antagonist, the activation of CREB, in response to either Dex, $\mathrm{E}_{2} \beta$ or dBcAMP, was efficiently prevented (Fig. 4). Taken together, these results indicate that, in CCRF-CEM cells, Dex-induced and $\mathrm{E}_{2} \beta$-induced CREB activation is mediated by cAMP. Effects of Dex and $E_{2} \beta$ mediated via cAMP, and involving probably non-genomic mechanisms, have also been reported in other cell types. ${ }^{25,31,44,45}$

The results presented in this work (Fig. 5A-C) and in our latest works ${ }^{4,16}$ show that, in CCRF-CEM cells, Dex and $E_{2} \beta$ induce the synthesis of ANXA1. Additionally, we found that treatment of the cells with dBcAMP was as effective as Dex and $E_{2} \beta$ in inducing ANXA1 synthesis (Fig. 5A-D). Furthermore, the cAMP antagonist Rp-8-Br-cAMPS effectively prevented ANXA1 synthesis in response to either one of those stimuli (Fig. 5E-G). Hence, these results indicate that cAMP is also part of the signaling pathway that leads to ANXA1 synthesis in CCRFCEM cells stimulated with either Dex or $\mathrm{E}_{2} \beta$. Moreover, the ability of Rp-8-Br-cAMPS to inhibit both CREB activation and ANXA1 expression, induced by either Dex, $E_{2} \beta$ or dBcAMP, strongly suggests that CREB is required for and mediates ANXA1 transcription in response to those stimuli. The ability of dBcAMP to activate both CREB and ANXA1 synthesis further supports this conclusion.

Members of the MAPK family, namely the p38 MAPK, have been implicated in the phosphorylation and subsequent activation of CREB in response to several stimuli. ${ }^{28,29,46}$ On the contrary, some reports indicate that Dex and $\mathrm{E}_{2} \beta$ can up-regulate p38 MAPK activity. ${ }^{36-38}$ To further elucidate the signaling mechanisms involved in Dex-induced and $\mathrm{E}_{2} \beta$-induced CREB activation and ANXA1 synthesis, we evaluated the role of the p38 MAPK in those processes by using the pyrydinyl imidazole compound SB203580, which is a specific inhibitor of this kinase. ${ }^{41-43}$ The results obtained show that SB203580 effectively prevented the activation of CREB (Fig. 6) and the synthesis of ANXA1 (Fig. 5H-J) induced by Dex, $\mathrm{E}_{2} \beta$ and dBcAMP. Therefore, the activity of the p38 MAPK seems to be indispensable for CREB activation and ANXA1 synthesis to occur in response to Dex, $E_{2} \beta$ and $\mathrm{ABCAMP}$. These results also indicate that CREB mediates ANXA1 expression induced by either one of these stimuli, in CCRF-CEM cells.

The involvement of CREB on ANXA1 expression induced by Dex, $E_{2} \beta$ or dBcAMP is further supported by the observation that two different agents, SB203580 and Rp-8-Br-cAMPS, acting by distinct mechanisms, were equally effective in preventing these processes. Furthermore, since SB203580 was also effective in preventing dBcAMP-induced CREB activation and ANXA1 synthesis, these results also indicate that, in CCRF-CEM cells, the p38 MAPK mediates those cAMP-induced responses. These re- 
sults are in agreement with several studies that indicate the p38 MAPK can be a downstream target of cAMP, thus participating in CAMP-dependent gene transcription, although the nature of the kinases that link cAMP to the p38 MAPK are still unknown. ${ }^{47,48}$

The ability of Dex and $E_{2} \beta$ to activate CREB through a signalling pathway involving cAMP and the p38 MAPK, as we observed in the present study, may also be implicated in other effects of GC hormones, besides ANXA1 synthesis. For instance, the p38 MAPK and the CAMP-dependent PKA are required for COX-2 expression in various cell types. ${ }^{49-51}$ Therefore, it would be possible that these hormones could also induce COX-2 expression in CCRF-CEM cells. Although we did not address this question directly, various studies have shown that GC hormones, namely Dex, reduce COX-2 expression, which, at least in some of those cells, is mediated by ANXA1. ${ }^{6-8}$ The ability of Dex to inhibit COX-2 expression can be an important mechanism underlying the anti-inflammatory actions of GC and their inhibitory effect on ceil proliferation. In fact, it was shown that the ability of Dex to inhibit the synthesis of prostaglandins by COX-2 is mediated by ANXA1, leading to the inhibition of cell proliferation. ${ }^{8}$ On the contrary, $\mathrm{E}_{2} \beta$ seems to have a dual role on COX-2 expression. In high concentrations, as those used in the present work, this hormone negatively modulates COX-2 expression, whereas in lower concentrations it can up-regulate COX-2 synthesis. ${ }^{52,53}$ Regardless of these discrepancies, several studies indicate that other transcription factors besides CREB, namely nuclear factor- $\mathrm{\kappa B}$, are required for $\mathrm{COX}-2$ synthesis in different cells and in response to a variety of stimuli. $^{50,55}$ Interestingly, we have recently observed that Dex $(1 \mu \mathrm{M})$ inhibits nuclear factor- $\kappa \mathrm{B}$ activity in CCRF-CEM cells, ${ }^{55}$ which suggests that, although activating CREB, Dex and $\mathrm{E}_{2} \beta$ cannot induce COX-2 expression in CCRF-CEM cells.

We have previously observed that neither the GC antagonist RU486 nor the oestrogen antagonist ICI 182,780 can prevent the synthesis of ANXA1, in response to Dex and $\mathrm{E}_{2} \beta$, respectively, in CCRFCEM cells. ${ }^{4,16}$ Thus, the ability of Dex and $\mathrm{E}_{2} \beta$ to induce ANXA1 synthesis seems to be independent of genomic mechanisms, mediated by the classical GC and oestrogen receptors, respectively. Instead, this action of both steroids may involve their binding to membrane GC or oestrogen receptors ${ }^{12,56-58}$ or alternatively, it may be mediated by non-specific interactions with the plasma membrane of CCRF-CEM cells. ${ }^{59,60}$

In summary, the results presented here suggest that, in CCRF-CEM cells, Dex-induced and $\mathrm{E}_{2} \beta$ induced ANXA1 expression requires the activation of the transcription factor CREB, which in turn seems to be mediated by cAMP and the p38 MAPK. These findings also suggest that, besides the nuclear steroid hormone receptors, other transcription factors, namely CREB, may play important roles in mediating the anti-inflammatory actions of GC and oestrogen hormones.

ACKNOWLEDGEMENTS. Margarida Castro-Caldas is supported by Fundação para a Ciencia e Tecnologia (Ph.D. Fellowship BD/2763/2000).

\section{References}

1. Goulding NJ, Euzger HS, Butt SK, Perretti M. Novel pathways for glucocorticoid effects on neutrophils in chronic inflammation. Inflamm Res 1998; 47: S158-S165.

2. Buckingham JC, Flower RJ. Lipocortin 1, a second messenger of glucocorticoid action in the hypothalamo-pituitary-adrenocortical axis. Mol Med Today 1997; 3: 296-302.

3. Perretti M. Lipocortin 1 and chemokine modulation of granulocyte and monocyte accumulation in experimental inflammation. Gen Pharmacol 1998; 31: 545- 552

4. Castro-Caldas M, Duarte CB, Carvalho AP, Lopes MC. $17 \beta$-estradiol promotes the synthesis and the secretion of annexin 1 in the CCRF-CEM human cell line. Mediat Inflamm 2001; 10: 245-251.

5. Yang Y, Hutchinson P, Santos LL, Morand EF. Glucocorticoid inhibition of adjuvant arthritis synovial macrophage nitric oxide production: role of lipocortin 1. Clin Exp Immunol 1998; 111: 117-122.

6. Ferreira SH, Cunha FQ, Lorenzetti BB, Michelin MA, Perretti M, Flower RJ, Poole S. Role of lipocortin-1 in the anti-hyperalgesic actions of dexamethasone. Br J Pharmacol 1997; 121: 883-888.

7. Minghetti L, Nicolini A, Polazzi E, Greco A, Perretti M, Parente L, Levi G. Down-regulation of microglial cyclo-oxygenase-2 and inducible nitric oxide synthase expression by lipocortin 1. Br J Pharmacol 1999; 126: $1307-1314$.

8. Croxtall JD, Gilroy DW, Solito E, Choudhury Q, Ward B, Buckingham JC, Flower RJ. Attenuation of glucocorticoid functions in an Anx $-/-$ cell line. Biochem J 2003; 371 (Part 3): 927-935.

9. Croxtall JD, Flower RJ. Lipocortin 1 mediates dexamethasone-induced growth arrest of the A549 lung adenocarcinoma cell line. Proc Natl Acad Sci USA 1992; 89: 3571-3575.

10. Kim SS, Oh OJ, Min HY, et al. Eugenol suppresses cyclooxigenase-2 expression in lipopolysaccharide-stimulated mouse macrophage RAW264.7 cells. Life Sci 2003; 73: 337-348.

11. Kassem M. Cellular and molecular effects of growth hormone and estrogen on human bone cells. APMIS 1997; 761: 1-30.

12. Stefano GB, Cadet P, Breton C, et al. Estradiol-stimulated nitric oxide release in human granulocytes is dependent on intracellular calcium transients: evidence for a cell surface estrogen receptor. Blood 2000; 95 : 3951-3958.

13. Taylor AD, Philip JG, John CD, Cover PO, Morris JF, Flower RJ, Buckingham JC. Annexin 1 (lipocortin 1) mediates the glucocorticoid inhibition of cyclic adenosine $3^{\prime}, 5^{\prime}$-monophosphate-stimulated prolactin secretion. Endocrinology 2000; 141: 2209-2219.

14. Coméra C, Russo-Marie F. Glucocorticoid-induced annexin 1 secretion by monocytes and peritoneal leukocytes. Br J Pharmacol 1995; 115: $1043-1047$

15. Sudlow AW, Carey F, Forder R, Rothwell NJ. Lipocortin-1 inhibits CRH stimulation of plasma ACTH and IL- $1 \beta$-stimulated hypothalamic CRH release in rats. Am J Physiol 1996; 270: R54-R60.

16. Castro-Caldas M, Duarte CB, Carvalho AP, Lopes MCF. Dexamethasone induces the secretion of annexin 1 in immature lymphoblastic cells by a calcium-dependent mechanism. Mol Cell Biochm 2002; 237: 31-38.

17. Barnes PJ. Anti-inflammatory actions of glucocorticoids: molecular mechanisms. Clin Sci 1998; 94: 557-572.

18. El Tanani MKK, Green CD. Two separate mechanisms for ligandindependent activation of the estrogen receptor. Mol Endocrinol 1997; 11: $928-937$.

19. Perretti M, Flower RJ. Measurement of lipocortin 1 levels in murine peripheral blood leukocytes by flow cytometry: modulation by glucocorticoids and inflammation. Br J Pharmacol 1996; 118: 605-610.

20. Solito E, De Coupade C, Parente L, Flower RJ, Russo-Marie F. Human annexin 1 is highly expressed during the differentiation of the epithelial cell line A 549: involvement of nuclear factor interleukin 6 in phorbol ester induction of annexin 1. Cell Growth Diff 1998; 9: 327-336.

21. Gebicke-Haerter PJ, Schobert A, Dieter P, Honegger P, Hertting G. Regulation and glucocorticoid-independent induction of lipocortin I in cultured astrocytes. J Neurochem 1991; 57: 175-183.

22. Antonicelli F, De Coupade C, Russo-Marie F, Le Garrec Y. CREB is involved in mouse annexin Al regulation by cAMP and glucocorticoids. Eur J Biochem 2001; 268: 62-69.

23. Donnelly SR, Moss SE. Functional analysis of the human annexin I and VI gene promoters. Biochem J 1998; 332: 681-687. 
24. Gu G, Rojo AA, Zee MC, Yu J, Simerly RB. Hormonal regulation of CREB phosphorylation in the anteroventral periventricular nucleus. J Neurosci 1996; 16: 3035-3044

25. Zhou Y, Watters JJ, Dorsa DM. Estrogen rapidly induces the phosphorylation of the cAMP response element binding protein in rat brain Endocrinology 1996; 137: 2163-2166.

26. Lin RZ, Chen J, Hu ZW, Hoffinan BB. Phosphorylation of the cAMP response element-binding protein and activation of transcription by al adrenergic receptors. J Biol Chem 1998; 273: 30033-30038.

27. Grewal SS, Fass DM, Yao H, Ellig CL, Goodman RH, Stork PJS. Calcium and cAMP signals differentially regulate cAMP-responsive elementbinding protein function via Rap 1-extracellular signal-regulated kinase pathway. J Biol Chem 2000; 275: 34433-34441.

28. Deak M, Clifton AD, Lucocq JM, Alessi DR. Mitogen- and stress-activated protein kinase-1 (MSK1) is directly activated by MAPK and SAPK2/p38, and may mediate activation of CREB. EMBOJ 1998; 17: 4426-4441.

29. Matos TJ, Duarte CB, Carvalho AP, Lopes C. Activation and physiological roles of the mitogen activated protein kinases (MAPKs). In Heilmeyer L, Friedrich P (eds). Protein Modules in Cellular Signalling 2001: 12-28.

30. Baus E, Van Laethem F, Andris F, Rolin S, Urbain J, Leo O. Dexamethasone increases intracellular cyclic AMP concentration in murine $\mathrm{T}$ lymphocyte cell lines. Steroids 2001; 66: 39-47.

31. Aksoy MO, Mardini IA, Yang Y, Bin W, Zhou S, Kelsen SG. Glucocorticoid effects on the beta-adrenergic receptor-adenylyl cyclase system of human airway epithelium. J Allergy Clin Immunol 2002; 109: 491-497.

32. Aronica SM, Kraus WL, Katzenellenbogen BS. Estrogen action via the cAMP signalling pathway: stimulation of adenylate cyclase and cAMPregulated gene transcription. Proc Natl Acad Sci USA 1994; 91: 85178521.

33. Sutter-Dub MT. Rapid non-genomic and genomic responses to progestogens, estrogens, and glucocorticoids in the endocrine pancreatic B cell, the adipocyte and other cell types. Steroids 2002; 67: 77-93.

34. Elbtaouri H, Antonicelli F, Claisse D, Delemer B, Haye B. Cyclic AMP regulation of annexins I, II, V synthesis and localization in cultured porcine thyroid cells. Biochimie 1994; 76: 417-422.

35. Mizuno H, Uemura K, Moriyama A, Wada Y, Asai K, Kimura S, Kato T. Glucocorticoid induced the expression of mRNA and the secretion of lipocortin 1 in rat astrocytoma cells. Brain Res 1997; 746: 256-264.

36. Zhang JP, Wong CK, Lam CW. Role of caspases in dexamethasoneinduced apoptosis and activation of c-Jun NH2-terminal kinase and p38 mitogen-activated protein kinase in human eosinophils. Clin Exp Immunol 2000; 122: 20-27.

37. Razandi M, Pedram A, Levin ER. Estrogen signals to the preservation of endothelial cell form and function. J Biol Chem 2000; 275: $38540-$ 38546.

38. Kelly MJ, Levin ER. Rapid actions of plasma membrane estrogen receptors. Trends Endocrinol Metab 2001; 12: 152-156.

39. Gomes ER, Cruz T, Lopes CF, Carvalho AP, Duarte CB. Photosentization of lymphoblastoid cells with phthalocyanines at different saturing incubation times. Cell Biol Toxicol 1999; 15: 249-260.

40. Gjertsen BT, Mellgren G, Otten A, et al. Novel (Rp)-cAMPS analogs as tools for inhibition of cAMP-kinase in cell culture. Basal cAMP-kinase activity modulates interleukin-1beta action. J Biol Chem 1995; 270 $20599-20607$.

41. Mendes AF, Caramona MM, Carvalho AP, Lopes MC. Role of mitogenactivated protein kinases and tyrosine kinases on IL-1-induced NF- $\mathrm{KB}$ activation and iNOS expression in bovine articular chondrocytes. Nitric Oxide 2002; 6: 35-44.

42. Herlaar E, Brown Z. p38 MAPK signalling cascades in inflammatory disease. Mol Med Today 1999; 5: 439-446.
43. Tong L, Pav S, White DM, et al . A highly specific inhibitor of human p38 MAP kinase binds in the ATP pocket. Nat Struct Biol 1997; 4: 311-316.

44. Michel MC, Knapp J, Ratjen H. Sensitization by dexamethasone of lymphocyte cyclic AMP formation: evidence for increased function of the adenylyl cyclase catalyst. Br J Pharmacol 1994; 113: 240-246.

45. Harvey BJ, Alzamora R, Healy V, Renard C, Doolan CM. Rapid responses to steroid hormones: from frog skin to human colon. A homage to Hans Ussing. Biochim Biophys Acta 2002; 1566: 116-128.

46. Sung JY, Shin SW, Ahn YS, Chung KC. Basic fibroblast growth factorinduced activation of novel CREB kinase during the differentiation of immortalized hippocampal cells. J Biol Chem 2001; 276: 13858-13866.

47. Cao W, Medvedev AV, Daniel KW, Collins S. $\beta$-Adrenergic activation of p38 MAP kinase in adipocytes. J Biol Chem 2001; 276: 27077-27082.

48. Chen CH, Zhang DH, La Porte JM, Ray A. Cyclic AMP activates p38 mitogen-activated protein kinase in Th2 cells: phosphorylation of GATA3 and stimulation of Th2 cytokine gene expression. J Immunol 2000; 165: $5597-5605$

49. Wadwha S, Choudhary S, Voznesensky M, Epstein M, Raisz L, Pilbeam C. Fluid flow induces COX-2 expression in MC3T3-E1 osteoblasts via a PKA signaling pathway. Biochem Biophys Res Commun 2002; 297: 46-51.

50. Billack B, Heck DE, Mariano TM, Gardner CR, Sur R, Laskin DL, Laskin JD. Induction of cyclooxigenase- 2 by heat shock protein 60 in macrophages and endothelial cells. Am J Physiol Cell Physiol 2002; 283: $\mathrm{C} 1267-\mathrm{C} 1277$

51. Tessner TG, Muhale F, Schoemann S, Cohn SM, Morrison A, Atenson WF Basic fibroblast growth factor upregulates cyclooxigenase-2 in 1407 cells through p38 MAP kinase. Am J Physiol Gastrointest Liver Physiol 2003; 284: G269-G279

52. Sato T, Michizu H, Hashizume K, Ito A. Hormonal regulation of PGE2 and COX-A-2 production in rabbit uterine cervical fibroblasts. $J$ Appl Physiol 2001; 90: 1227-1231.

53. Akarasereenont P, Techatraisak K, Thaworn A, Chotewuttakorn S. The induction of cyclooxygenase- 2 by 17 beta-estradiol in endothelial cells is mediated through protein kinase C. Inflamm Res 2000; 49: 460-465.

54. Yeo SJ, Gravis D, Yoon JG, Yi AK. Myeloid differentiation factor 88dependent transcriptional regulation of cyclooxigenase- 2 expression by CpG DNA: role of NF-kappa B and p38. J Biol Chem 2003; 278: 2256322573.

55. Castro-Caldas M, Mendes AF, Duarte CB, Lopes MC. Dexamethasone prevents interleukin- $1 \beta$-induced NF- $\kappa$ B activation by upregulating I $\kappa \mathrm{B}-\alpha$ synthesis, in lymphoblastic cells. Med Inflamm 2003; 12: 37-46.

56. Powell CE, Watson CS, Gametchu B. Immunoaffinity isolation of native membrane glucocorticoid receptor from S- $49++$ lymphoma cells biochemical characterization and interaction with Hsp 70 and Hsp 90 Endocrine 1999; 10: 271-280.

57. Berki T, Palinkas L, Boldizsar F, Nemeth P. Glucocorticoid (GC) sensitivity and GC receptor expression differ in thymocyte subpopulations. Int Immunol 2002; 14: 463-469.

58. Doolan CM, Harvey BJ. A Galphas protein-coupled membrane receptor, distinct from the classical oestrogen receptor, transduces rapid effects of oestradiol on $[\mathrm{Ca}(2+)](\mathrm{i})$ in female rat distal colon. Mol Cell Endocrinol 2003; 199: $87-103$

59. Buttgereit F, Scheffold A. Rapid glucocorticoid effects on immune cells. Steroids 2002; 67: 529-534

60. Pitzalis C, Pipitone N, Perretti M. Regulation of leukocyte-endothelial interactions by glucocorticoids. Ann NY Acad Sci 2002; 966: 108-118.

\section{Received 6 August 2003}

Accepted 15 September 2003 


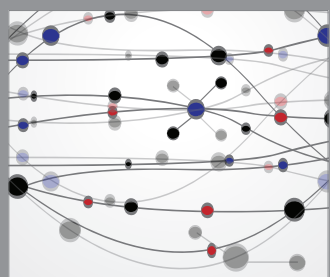

The Scientific World Journal
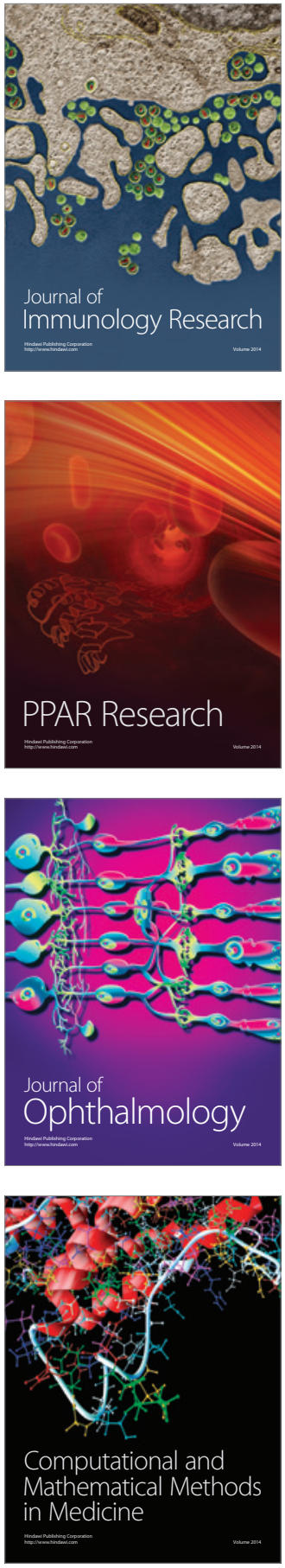

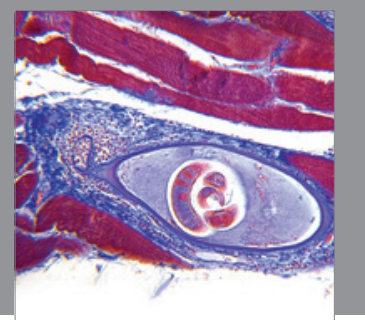

Gastroenterology

Research and Practice
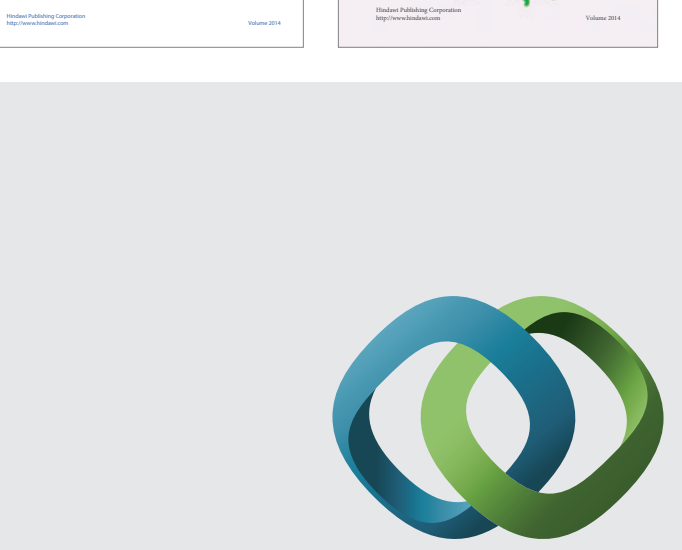

\section{Hindawi}

Submit your manuscripts at

http://www.hindawi.com
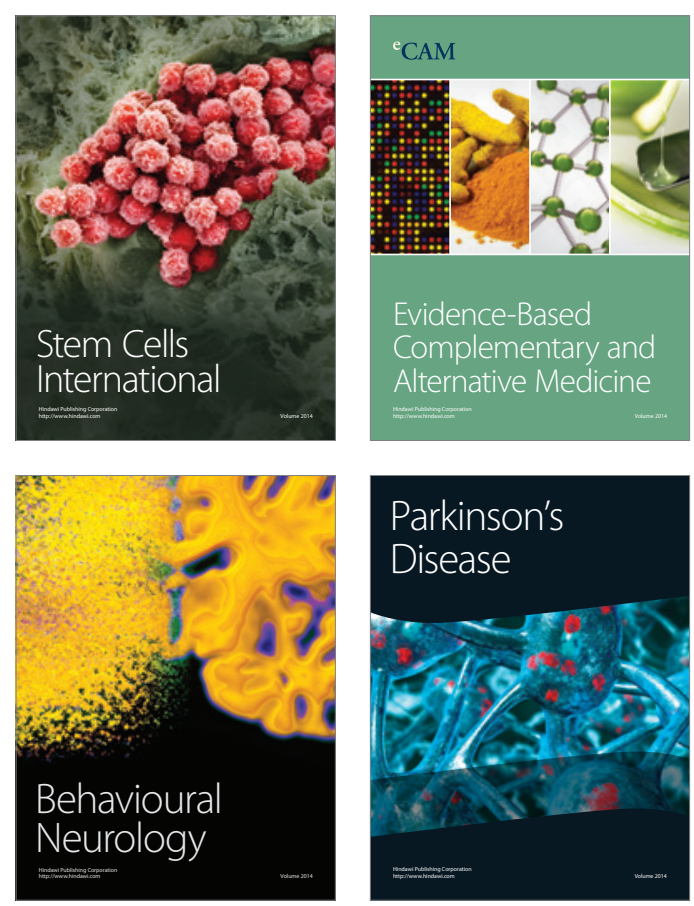

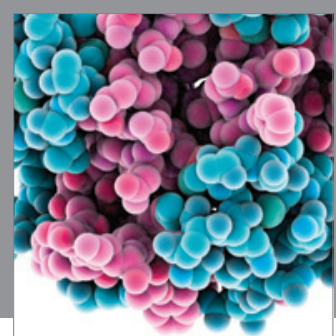

Journal of
Diabetes Research

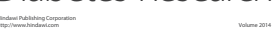

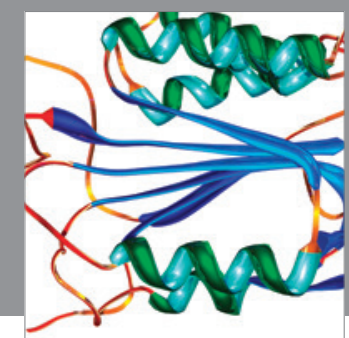

Disease Markers
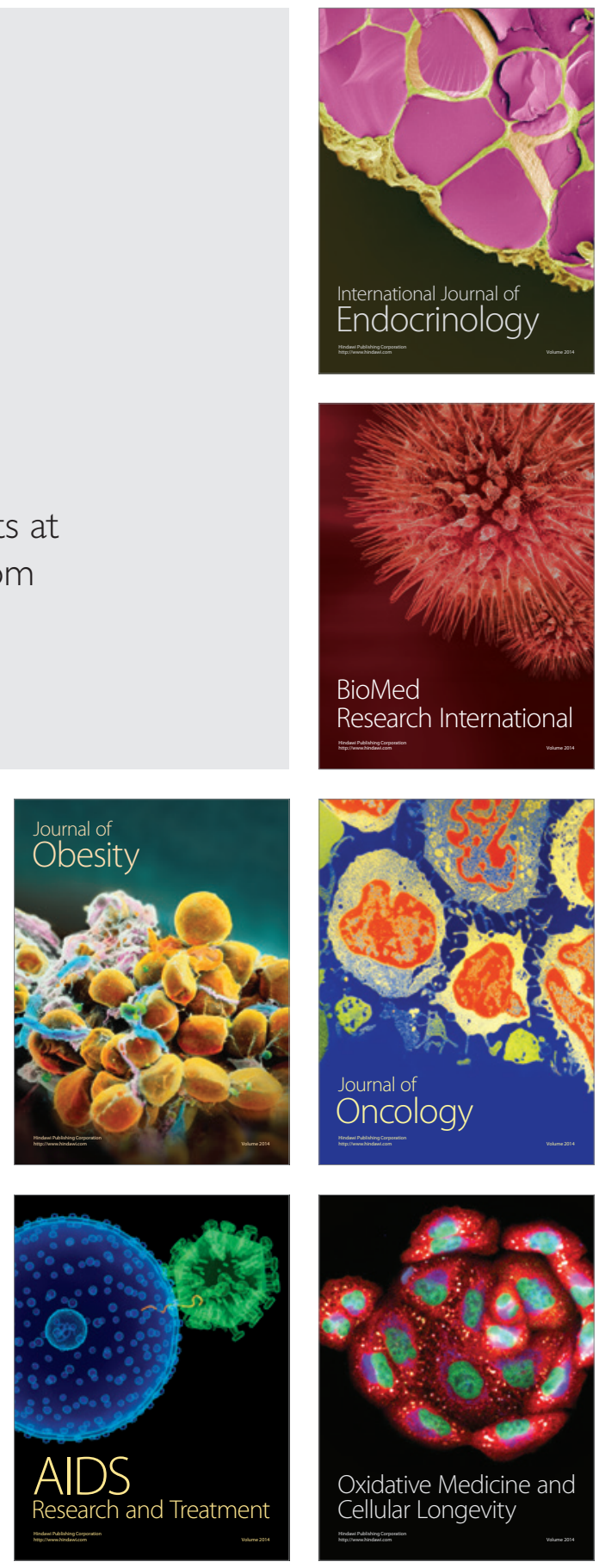